\title{
Clinical Comparative study of the effect of preoperative pregabalin on reduction of the incidence of headache after spinal anesthesia in cesarean section
}

\author{
${ }^{1}$ Mohsen Mohamed El -guoshy, ${ }^{1}$ El-sayed Mostafa Mohamed Ali Stohy ${ }^{2}$ Hossam-aldin Hussein \\ Kamel Sale, ${ }^{1}$ Abdalwahab Abdelsatar Saleh, ${ }^{1}$ Mahmoud Mohamed Mohamed Abdallah Seliem \\ ${ }^{1}$ Department of Anesthesiology and Intensive care, Faculty of Medicine Al- Azhar University \\ ${ }^{2}$ Department of Obstetrics and Gynaecology, Faculty of Medicine Al- Azhar University \\ Corresponding author: Mahmoud Mohamed Mohamed Abdallah Seliem, Mobile: 01126781817, Email: \\ seliemmahmoud@gmail.com
}

\begin{abstract}
Background: Post dural puncture headache (PDPH) is unpleasant complication following dural puncture. Incidence of PDPH following dural puncture range from $0.3 \%$ to $20 \%$ in spinal anesthesia. The incidence rate of PDPH is related to age, gender, needle size, pregnancy and previous history of PDPH.PDPH is characterized by severe, dull non throbbing pain aggravated by sitting or erect position, coughing, sneezing or straining and diminished in supine position. Objective: To evaluate the effect of preoperative administration of oral pregabalin $(150 \mathrm{mg}$ ) before cesarean section on the incidence of post dural puncture headache, postoperative nausea and vomiting and postoperative shivering, motor block, time to rescue analgesia, time of two segment regression and Apgar score of baby at 1 and 5 minute.

Patients and Methods: A prospective randomized study that was done in Alazhar University Hospitals after approval of ethical committee, An informed consent was obtained from the patients.

Results: The incidence of post dural puncture headache, postoperative nausea and vomiting and postoperative shivering were significantly lower at pregabalin groups. Time to rescue analgesia and time of two segment regression were significantly longer at pregabalin groups. Patients at pregabalin groups reach modified Bromage motor scale grade $\mathbf{3}$ earlier than patients at groups without pregabalin.

Conclusion: Preoperative oral pregabalin $150 \mathrm{mg}$ before cesarean section reduced the incidence of PDPH, postoperative nausea and vomiting and postoperative shivering, beside the earlier onset of motor block with increase duration of analgesia and time of two segment regression with no effect on baby.
\end{abstract}

\section{INTRODUCTION}

PDPH is a complication of regional anesthesia, more often seen in parturients, because of their risk factors of young age and female gender. In spinal anesthesia, the PDPH is mainly dependent on the size and type of needle. Before starting treatment, confirmation of diagnosis is essential because $5-16 \%$ of headaches after dural puncture are not PDP ${ }^{(1)}$.

The characteristic manifestation of PDPH is its postural component. It increases with sitting or standing and improves with supine position. The pain occurs in the temporal, frontal, or occipital regions bilaterally and can be associated with backache, nausea, neck stiffness, cranial nerve signs, and localized muscle spasms. A history of dural puncture and postural component of the headache are important in diagnosis ${ }^{(I)}$.

The most accepted mechanism for induction of headache is leakage of cerebrospinal fluid through dural hole resulting in cerebral vasodilatation, increased arterio-venous pressure gradient, dural traction and compression of cranial contents from loss of the cranial fluid cushion. It is important to differentiate PDPH from other causes as tension headache, migraine headache, drug withdrawal, preeclampsia, meningitis, and subarachnoid hemorrhage. Current treatment for PDPH involves complete bed rest, hydration, analgesics, oral or intravenous caffeine, sumatriptan, ACTH, corticosteroids and epidural patch ${ }^{(2)}$.

Pregabalin is an antiepileptic drug, it is a structural analogue of gammaaminobutyric acid (GABA), and it is effective in reducing hyperalgesia and may play an important role in acute postoperative pain ${ }^{(3)}$.

\section{AIM OF THE WORK}

This study was designed to evaluate the prophylactic effect of pregabalin on post- 
dural puncture headache incidence, incidence of postoperative shivering ,nausea and vomiting, time of two segment regression, motor block and Apgar score in patient undergoing spinal anesthesia for cesarean section.

\section{Patients and Methods}

This is a prospective randomized study that was done in Alazhar University Hospitals after approval of ethical committee, An informed consent was obtained from the patients.

Inclusion Criteria: Pregnant female. ASA class I or II patients. Patients undergoing elective cesarean section.

Exclusion Criteria: ASA III, IV and V class patients. Patients who had history of convulsion. Patients with known allergy to local anesthetic or to the study drug. Patients who had any contraindications to regional anesthesia (e.g., patient refusal, local infection, coagulation abnormality and tight mitral stenosis). Patients with chronic headache.Patients undergoing urgent cesarean section.

This study was conducted on 400 patients that was classified into four groups:- Group I (control group 1): Dural puncture that was performed by Quincke spinal needle without giving pregabalin preoperatively. -Group II: Dural puncture that was performed by Quincke spinal needle with giving pregabalin $150 \quad \mathrm{mg} \quad 2-4$ hours preoperatively. -Group III (control group 2): Dural puncture that was performed by pencil point spinal needle without giving pregabalin preoperatively. -Group IV: Dural puncture that was performed by pencil point spinal needle with giving pregabalin $150 \mathrm{mg} \mathrm{2-4}$ hours preoperatively .

Management of anesthesia: During the pre-anesthetic checkup visit, all patients were informed about the study. Pregabalin 150 mg was given 2-4 hours preoperatively.In the operating room IV cannula $18 \mathrm{G}$ was inserted and IV fluids at a rate of $10 \mathrm{ml} / \mathrm{kg}$ was started. Standard monitoring was done (ECG, pulse rate, non-invasive blood pressure and pulse oximetry). Spinal anesthesia was performed under strict aseptic technique in the sitting position. $2 \mathrm{ml}$ of lidocaine $2 \%$ for local infiltration of skin at L4-L5 space. Then,insertion of spinal needle $25 \mathrm{G}$ (pencil point or quincke bevel) by midline approach. When free flow of CSF was obtained, $2.2 \mathrm{ml}$ of heavy bupivacaine $0.5 \%$ was injected. Then, spinal needle was withdrawn and the patient was put in supine position immediately. Oxygen was supplied to the patient by face mask to maintain oxygen saturation at normal range. Regular monitoring of blood pressure, pulse and oxygen saturation was done. After delivery of baby, Apgar score was evaluated by pediatric resident. At the end of surgery, the patients were transferred to PACU where they were monitored and received supplemental oxygen by face mask, then they were shifted to the ward.

\section{Statistical analysis:}

Recorded data were analyzed using the statistical package for social sciences, version 20.0 (SPSS Inc., Chicago, Illinois, USA). Quantitative data were expressed as mean \pm standard deviation (SD). Qualitative data were expressed as frequency and percentage.

The following tests were done: Independent-samples t-test of significance was used when comparing between two means. Kruskall Wallis test: for multiple-group comparisons in non-parametric data. Chisquare $\left(\mathrm{x}^{2}\right)$ test of significance was used in order to compare proportions between two qualitative parameters. The confidence interval was set to $95 \%$ and the margin of error accepted was set to $5 \%$. So, the p-value was considered significant as the following: Probability (P-value): P-value $\leq 0.05$ was considered significant. P-value $\leq 0.001$ was considered as highly significant. P-value $>0.05$ was considered insignificant.

\section{RESULTS}

Comparison between groups I and II concerning the onset time to modified Bromage motor scale grade 3 showed statistically significant difference with earlier time at pregabalin group (table 1).

Comparison between groups III and IV in regard to onset time to modified Bromage motor scale grade 3 showed statistically significant difference with earlier time at pregabalin group (table 1).

Table (1): Comparison between groups in regard to onset time to modified Bromage motor scale grade 3 


\begin{tabular}{|l|c|c|c|c|}
\hline & $\begin{array}{c}\text { Group } \\
\text { I } \\
(\mathbf{N}=\mathbf{1 0 0} \\
)\end{array}$ & $\begin{array}{c}\text { Group } \\
\text { II } \\
(\mathbf{N = 1 0 0} \\
)\end{array}$ & $\begin{array}{c}\text { Group } \\
\text { III } \\
(\mathbf{N}=\mathbf{1 0 0} \\
)\end{array}$ & $\begin{array}{c}\text { Group } \\
\text { IV } \\
(\mathbf{N = 1 0 0} \\
)\end{array}$ \\
\hline $\begin{array}{l}\text { Onset time } \\
\text { to Bromage } \\
\text { score grade } \\
\mathbf{3}\end{array}$ & $14 \pm 2$ & $10 \pm 2$ & $15 \pm 2$ & $11 \pm 2$ \\
\hline $\begin{array}{l}\text { Independen } \\
\text { t Sample t- } \\
\text { test }\end{array}$ & \multicolumn{2}{|c|}{14.142} & \multicolumn{2}{|c|}{10.607} \\
\hline p-value & \multicolumn{2}{|c|}{$<\mathbf{0 . 0 0 1} *$ HS } & \multicolumn{2}{|c|}{$<\mathbf{0 . 0 0 1} *$ HS } \\
\hline
\end{tabular}

I: Qunicke needle group II: Qunicke needle+pregabalin group III: Pencil point needle group IV: Pencil point needle+pregabalin group F-ANOVA test; **p-value $<0.001 \mathrm{H}$

Comparison between all groups as regards Apgar score at $1 \mathrm{~min}$ showed no statistically significant difference with no effect on baby (table 2).

Table (2): Comparison between groups in regard to Apgar score at $1 \mathrm{~min}$.

\begin{tabular}{|c|c|c|c|c|c|c|}
\hline & $\begin{array}{c}\text { Group I } \\
(\mathbf{N}=100)\end{array}$ & $\begin{array}{c}\text { Group II } \\
(\mathbf{N}=100)\end{array}$ & $\begin{array}{c}\text { Group } \\
\text { III } \\
(\mathbf{N}=100)\end{array}$ & $\begin{array}{c}\text { Group } \\
\text { IV } \\
(\mathbf{N}=100)\end{array}$ & H & $\begin{array}{c}\text { p- } \\
\text { value }\end{array}$ \\
\hline $\begin{array}{c}\text { Apgar } \\
\text { score } \\
\text { at 1 } \\
\text { minute }\end{array}$ & $8.32 \pm 0.12$ & $8.15 \pm 0.11$ & $8.40 \pm 0.12$ & $8.23 \pm 0.11$ & 2.941 & 0.471 \\
\hline
\end{tabular}

I: Qunicke needle group II: Qunicke needle+pregabalin group III: Pencil point needle group IV: Pencil point needle+pregabalin group H-Kruskal Wallis; p-value $>0.05 \mathrm{NS}$

Comparison between all groups according to Apgar score at 5 min showed no statistically significant difference with no effect on baby (table 3).

Table (3): Comparison between groups concerning Apgar score at $5 \mathrm{~min}$.

\begin{tabular}{|c|c|c|c|c|c|c|}
\hline $\begin{array}{c}\text { Apgar } \\
\text { score } \\
\text { at 5 } \\
\text { minut } \\
\text { e }\end{array}$ & $\begin{array}{c}\text { Group I } \\
(\mathbf{N}=\mathbf{1 0 0})\end{array}$ & $\begin{array}{c}\text { Group II } \\
(\mathbf{N}=\mathbf{1 0 0})\end{array}$ & $\begin{array}{c}\text { Group } \\
\text { III } \\
(\mathbf{N = 1 0 0})\end{array}$ & $\begin{array}{c}\text { Group } \\
\text { IV } \\
(\mathbf{N}=100)\end{array}$ & H & $\begin{array}{c}\text { p- } \\
\text { valu } \\
\text { e }\end{array}$ \\
\hline $\begin{array}{c}\text { Apgar } \\
\text { score } \\
\text { at 5 } \\
\text { minut } \\
\text { e }\end{array}$ & $\begin{array}{c}9.36 \pm 0.1 \\
4\end{array}$ & $\begin{array}{c}9.17 \pm 0.1 \\
3\end{array}$ & $\begin{array}{c}9.40 \pm 0.1 \\
3\end{array}$ & $\begin{array}{c}9.21 \pm 0.1 \\
2\end{array}$ & $\begin{array}{c}0.13 \\
8\end{array}$ & $\begin{array}{c}0.63 \\
8\end{array}$ \\
\hline
\end{tabular}

I: Qunicke needle group II: Qunicke needle+pregabalin group III: Pencil point needle group IV: Pencil point needle+pregabalin group H-Kruskal Wallis;; p-value $>0.05 \mathrm{NS}$

Comparison between groups I and II regarding shivering showed statistically significant difference with less number of shivering at pregabalin group (table 4).

Comparison between groups III and IV concerning shivering showed statistically significant difference with less number of shivering at pregabalin group (table 4).
Table (4): Comparison between groups about shivering.

\begin{tabular}{|c|c|c|c|c|}
\hline Shivering & $\begin{array}{c}\text { Group } \\
\text { I } \\
(\mathbf{N}=\mathbf{1 0 0})\end{array}$ & $\begin{array}{c}\text { Group } \\
\text { II } \\
(\mathbf{N}=100)\end{array}$ & $\begin{array}{l}\text { Group } \\
\text { III } \\
(\mathbf{N}=100)\end{array}$ & $\begin{array}{c}\text { Group IV } \\
(\mathbf{N}=\mathbf{1 0 0})\end{array}$ \\
\hline Yes & $\begin{array}{c}15 \\
(15 \%) \\
\end{array}$ & $5(5 \%)$ & $\begin{array}{c}13 \\
(13 \%) \\
\end{array}$ & $2(2 \%)$ \\
\hline No & $\begin{array}{c}85 \\
(85 \%)\end{array}$ & $\begin{array}{c}95 \\
(95 \%)\end{array}$ & $\begin{array}{c}87 \\
(87 \%)\end{array}$ & $98(98 \%)$ \\
\hline $\begin{array}{l}\text { Chi-square } \\
\text { test }\end{array}$ & \multicolumn{2}{|c|}{4.500} & \multicolumn{2}{|c|}{7.207} \\
\hline p-value & \multicolumn{2}{|c|}{$0.034 * \mathrm{~S}$} & \multicolumn{2}{|c|}{$0.007 * \mathrm{~S}$} \\
\hline
\end{tabular}

I: Qunicke needle group II: Qunicke needle+pregabalin group III: Pencil point needle group IV: Pencil point needle+pregabalin group $x^{2}$ : Chi-square test; *p-value $<0.05 \mathrm{~S}$

Comparison between groups I and II regarding postoperative nausea and vomiting showed statistically significant difference with less number of PONV at pregabalin group as shown in table (5).

Comparison between groups III and IV according to postoperative nausea and vomiting showed statistically significant difference with less number of PONV at pregabalin group as shown in table (5).

Table (5): Comparison between groups concerning post-operative nausea and vomiting.

\begin{tabular}{|c|c|c|c|c|}
\hline $\begin{array}{c}\text { Post- } \\
\text { operative } \\
\text { nausea } \\
\text { and } \\
\text { vomiting }\end{array}$ & $\begin{array}{l}\text { Group } \\
\qquad \\
(\mathrm{N}=100)\end{array}$ & $\begin{array}{l}\text { Group } \\
\text { II } \\
(\mathrm{N}=100)\end{array}$ & $\begin{array}{l}\text { Group } \\
\text { III } \\
(\mathbf{N}=100)\end{array}$ & $\begin{array}{c}\text { Group IV } \\
(\mathbf{N}=100)\end{array}$ \\
\hline Yes & $\begin{array}{c}22 \\
(22 \%)\end{array}$ & $\begin{array}{c}10 \\
(10 \%)\end{array}$ & $\begin{array}{c}24 \\
(24 \%)\end{array}$ & $12(12 \%)$ \\
\hline No & $\begin{array}{c}78 \\
(78 \%) \\
\end{array}$ & $\begin{array}{c}90 \\
(90 \%) \\
\end{array}$ & $\begin{array}{c}76 \\
(76 \%) \\
\end{array}$ & $88(88 \%)$ \\
\hline $\begin{array}{l}\text { Chi-square } \\
\text { test }\end{array}$ & \multicolumn{2}{|c|}{4.501} & \multicolumn{2}{|c|}{4.099} \\
\hline p-value & \multicolumn{2}{|c|}{$0.034 * \mathrm{~S}$} & \multicolumn{2}{|c|}{$0.043 * \mathrm{~S}$} \\
\hline \multicolumn{5}{|c|}{$\begin{array}{l}\text { I: Qunicke needle group II: Qunicke needle+pregabalin } \\
\text { group III: Pencil point needle group IV: Pencil point } \\
\text { needle+pregabalin group } x^{2}: \text { Chi-square test; *p-value } \\
<0.05 \mathrm{~S}\end{array}$} \\
\hline
\end{tabular}

about time to rescue analgesia showed statistically significant difference with longer time at pregabalin group (table 6).

Comparison between groups III and IV concerning time to rescue analgesia showed statistically significant difference with longer time at pregabalin group (table 6). 
Table (6): Comparison between groups regarding time to rescue analgesia ( $\mathrm{min})$.

\begin{tabular}{|c|c|c|c|c|}
\hline & $\begin{array}{c}\text { Group } \\
\text { I } \\
(\mathbf{N}=100)\end{array}$ & $\begin{array}{c}\text { Group } \\
\text { II } \\
(\mathbf{N}=100)\end{array}$ & $\begin{array}{c}\text { Group } \\
\text { III } \\
(\mathbf{N}=100)\end{array}$ & $\begin{array}{c}\text { Group } \\
\text { IV } \\
(\mathbf{N}=100)\end{array}$ \\
\hline $\begin{array}{c}\text { Time to } \\
\text { rescue } \\
\text { analgesia } \\
(\mathrm{min})\end{array}$ & $160 \pm 30$ & $220 \pm 30$ & $155 \pm 40$ & $225 \pm 20$ \\
\hline $\begin{array}{l}\text { Independent } \\
\text { Sample t- } \\
\text { test }\end{array}$ & \multicolumn{2}{|c|}{14.142} & \multicolumn{2}{|c|}{15.623} \\
\hline p-value & \multicolumn{2}{|c|}{$<0.001 * *$ HS } & \multicolumn{2}{|c|}{$<0.001 * *$ HS } \\
\hline
\end{tabular}

I: Qunicke needle group II: Qunicke needle+pregabalin group III: Pencil point needle group IV: Pencil point needle + pregabalin group F-ANOVA test; **p-value $<0.001 \mathrm{HS}$

Comparison between groups I and II about time of two segment regression showed statistically significant difference with longer time at pregabalin group as shown in table (7).

Comparison between groups III and IV concerning time of two segment regression showed statistically significant difference with longer time at pregabalin group as shown in table (7).

Table (7): Comparison between groups regarding time of two segment regression (min).

\begin{tabular}{|c|c|c|c|c|}
\hline & $\begin{array}{c}\text { Group } \\
\text { I } \\
(\mathrm{N}=\mathbf{1 0 0})\end{array}$ & $\begin{array}{c}\text { Group } \\
\text { II } \\
(\mathbf{N}=\mathbf{1 0 0})\end{array}$ & $\begin{array}{c}\text { Group } \\
\text { III } \\
(\mathbf{N}=100)\end{array}$ & $\begin{array}{c}\text { Group } \\
\text { IV } \\
(\mathbf{N}=100)\end{array}$ \\
\hline $\begin{array}{l}\text { Time to two } \\
\text { segment } \\
\text { progression } \\
\text { (minute) }\end{array}$ & $80 \pm 10$ & $100 \pm 15$ & $85 \pm 10$ & $95 \pm 20$ \\
\hline $\begin{array}{l}\text { Independent } \\
\text { Sample t- } \\
\text { test }\end{array}$ & \multicolumn{2}{|c|}{11.094} & \multicolumn{2}{|c|}{4.472} \\
\hline p-value & \multicolumn{2}{|c|}{$<0.001 * *$ HS } & \multicolumn{2}{|c|}{$<0.001 * *$ HS } \\
\hline $\begin{array}{l}\text { I: Qunic } \\
\text { needle }+ \text { pre } \\
\text { group IV: } \\
\text { F-ANOVA }\end{array}$ & $\begin{array}{l}e \quad \text { need } \\
\text { abalin gr }\end{array}$ & $\begin{array}{l}\text { grou } \\
\text { up III: }\end{array}$ & $\begin{array}{l}\text { II: } \\
\text { ncil poit } \\
\text { regabal } \\
\text { HS }\end{array}$ & $\begin{array}{l}\text { onicke } \\
\text { needle } \\
\text { group }\end{array}$ \\
\hline
\end{tabular}

Comparison between groups I and II regarding incidence of headache showed statistically significant difference with less number of headache at pregabalin group as shown in table (8).

Comparison between groups III and IV about incidence of headache showed statistically significant difference with less number of headache at pregabalin group as shown in table (8).
Table (8): Comparison between groups concerning incidence of headache.

\begin{tabular}{|l|c|c|c|c|}
\hline $\begin{array}{l}\text { Incidence } \\
\text { of } \\
\text { headache }\end{array}$ & $\begin{array}{c}\text { Group } \\
\text { I } \\
(\mathbf{N = 1 0 0})\end{array}$ & $\begin{array}{c}\text { Group } \\
\text { II } \\
(\mathbf{N = 1 0 0})\end{array}$ & $\begin{array}{c}\text { Group } \\
\text { III } \\
(\mathbf{N = 1 0 0})\end{array}$ & $\begin{array}{c}\text { Group IV } \\
(\mathbf{N}=\mathbf{1 0 0})\end{array}$ \\
\hline Yes & $\begin{array}{c}35 \\
(35 \%)\end{array}$ & $\begin{array}{c}15 \\
(15 \%)\end{array}$ & $\begin{array}{c}12 \\
(12 \%)\end{array}$ & $7(7 \%)$ \\
\hline No & $\begin{array}{c}65 \\
(65 \%)\end{array}$ & $\begin{array}{c}85 \\
(85 \%)\end{array}$ & $\begin{array}{c}88 \\
(88 \%)\end{array}$ & $93(93 \%)$ \\
\hline $\begin{array}{l}\text { Chi- } \\
\text { square } \\
\text { test }\end{array}$ & \multicolumn{2}{|c|}{9.627} & \multicolumn{2}{|c|}{3.414} \\
\hline p-value & \multicolumn{2}{|c|}{$\mathbf{0 . 0 0 2} * \mathbf{S}$} & \multicolumn{2}{|c|}{$\mathbf{0 . 0 3 9} * \mathbf{S}$} \\
\hline
\end{tabular}

I: Qunicke needle group II: Qunicke needle+pregabalin group III: Pencil point needle group IV: Pencil point needle+pregabalin group $x^{2}$ : Chi-square test; **p-value $<0.001 \mathrm{HS}$

Comparison between 2nd day and 3rd day of onset of headache at Group I showed statistically non- significant difference between the 2 days (table 9).

Comparison between 2nd day and 3rd day of onset of headache at Group II showed statistically significant difference with most of cases at 3rd day (table 9).

Comparison between 2nd day and 3rd day of onset of headache at Group III showed statistically non- significant difference between the 2 days (table 9).

Comparison between 2nd day and 3rd day of onset of headache at Group IV showed statistically significant difference with most of cases at 3rd day (table 9).

Table (9): Comparison between groups about the onset of headache.

\begin{tabular}{|l|c|c|c|c|}
\hline $\begin{array}{c}\text { Onset of } \\
\text { headache }\end{array}$ & $\begin{array}{c}\text { Group I } \\
(\mathbf{N}=35)\end{array}$ & $\begin{array}{c}\text { Group } \\
\text { II } \\
(\mathbf{N = 1 5})\end{array}$ & $\begin{array}{c}\text { Group } \\
\text { III } \\
(\mathbf{N = 1 2})\end{array}$ & $\begin{array}{c}\text { Group IV } \\
(\mathbf{N}=7)\end{array}$ \\
\hline $1^{\text {st }}$ day & $0(0 \%)$ & $0(0 \%)$ & $0(0 \%)$ & $0(0 \%)$ \\
\hline $2^{\text {nd }}$ day & $\begin{array}{c}19 \\
(54.3 \%)\end{array}$ & $\begin{array}{c}3 \\
(20 \%)\end{array}$ & $\begin{array}{c}7 \\
(58.3 \%)\end{array}$ & $1(14.3 \%)$ \\
\hline $3^{\text {rd }}$ day & $\begin{array}{c}16 \\
(45.7 \%)\end{array}$ & $\begin{array}{c}12 \\
(80 \%)\end{array}$ & $\begin{array}{c}5 \\
(41.7 \%)\end{array}$ & $6(85.7 \%)$ \\
\hline $\begin{array}{l}\text { Chi-square } \\
\text { test }\end{array}$ & 0.231 & 8.533 & 0.164 & 4.567 \\
\hline $\begin{array}{l}\text { p-value } \\
\text { within } \\
\text { group }\left(2^{\text {nd }}\right. \\
\text { day and } 3^{\text {rd }} \\
\text { day) }\end{array}$ & 0.631 & $0.003 *$ & 0.686 & $0.033^{*}$ \\
\hline
\end{tabular}

I: Qunicke needle group II: Qunicke needle+pregabalin group III: Pencil point needle group IV: Pencil point needle + pregabalin group $x^{2}$ : Chi-square test; *p-value $<0.001 \mathrm{~S} ;{ }^{* *}$ p-value <0.001 HS; $p$-value >0.05 NS 


\section{DISCUSSION}

Post dural punctural headache (PDPH) is unpleasant complication following dural puncture. Incidence of PDPH following dural puncture ranged from $0.3 \%$ to $20 \%$ in spinal anesthesia ${ }^{(4)}$.

The incidence rate of PDPH is related to age, gender, needle size, pregnancy and previous history of PDPH.PDPH is characterized by severe, dull non thrombing pain, often fronto-occipital. It is aggravated by sitting or erect position, coughing, sneezing or straining and diminished in supine position.It may be associated by nausea, vomiting or visual disturbance. Headache start one or two days after spinal anesthesia and if left untreated, relieved spontaneously after a week (4).

The real etiology of PDPH is not fully understood, but mostly the decreased CSF volume because of CSF leakage leading to reduced pressure and cerebral venodilation ${ }^{(5)}$.

Pregabalin is an antiepileptic drug, it is a structural analogue of gammaaminobutyric acid (GABA), and it is effective in reducing hyperalgesia and may play an important role in acute post- operative pain in human ${ }^{(6)}$.

In our study, we evaluated the effectiveness of preoperative pregabalin at many parameters including: Incidence of postdural puncture headache during 72 hours postoperatively, Apgar score at 1 minute and 5 minute, post-operative shivering, postoperative nausea and vomiting, time to rescue analgesia in minutes (VAS score > 3) and onset time to modified Bromage scale grade 3 (min).

As regards the effect of pregabalin at postdural puncture headache, we found that pregabalin group has lower incidence of headache and delayed onset.

El Rahmawy et al. ${ }^{(7)}$ analyzed 86 randomized, controlled trials examining the efficacy of prophylactic pregabalin $(150 \mathrm{mg})$ on postdural puncture headache incidence after spinal anesthesia. They concluded that Preoperative oral pregabalin $150 \mathrm{mg}$ reduced the incidence and severity of PDPH but no effect on its onset.

Huseyinoglu and coworkers ${ }^{(8)}$ found that oral pregabalin was effective in treatment of PDPH after spinal anesthesia or diagnostic and/or therapeutic lumbar puncture.

In an analytic study conducted on 90 patients by Mahoori et al. ${ }^{(9)}$ to compare the effect of pregabalin, gabapentin, and acetaminophen on post-dural puncture headache, they concluded that pregabalin and gabapentin are both useful and safe in management of PDPH, but pregabalin is more effective in this regard and these were approaching our outcomes.

Moghaddam et al. $^{\left({ }^{(10)}\right.}$ reported that both pregabalin and gabapentin effectively reduced the severity of pain in PDPH and pregabalin seemed to be more efficient compared to gabapentin.

In contrast, Nofal $\boldsymbol{e t}$ al. ${ }^{(11)}$ compared the effects of gabapentin (structurally related compound to pregabalin) on characteristics of post-dural puncture headache in parturients undergoing cesarean section with spinal anesthesia. Women were randomized to receive preoperative gabapentin $600 \mathrm{mg}$ or placebo. They concluded that pre-operative administration of gabapentin had no effect on incidence of (PDPH) but delays its onset in parturients without significant adverse effects on the mother or the baby.

As regards time to first rescue analgesia, it was longer in pregabalin-treated patients and this is consistent with Induja $\boldsymbol{e t}$ al. ${ }^{(12)}$ study that was conducted on patients undergoing lower abdominal and lower limb surgery under spinal anesthesia . They concluded that preemptive oral pregabalin 150 $\mathrm{mg}$ reduced time to first rescue analgesia compared to gabapentin and placebo.

Also our study results is in accordance with Ghai $\boldsymbol{e t}$ al. ${ }^{(13)}$ study as they have noticed that the time to first rescue analgesia was significantly longer in pregabalin treated patients than gabapentin and control patients. At variance to our study ,Jokela et al. ${ }^{\text {(14) }}$ concluded that there was no difference between patients using preoperative medication with oral pregabalin $(75 \mathrm{mg})$ and placebo patients regarding the time to first analgesia request and this could possibly be due to a smaller dose (75mg).

Agarwal and co-workers (15), observed that a single preoperative dose of pregabalin $150 \mathrm{mg}$ is an effective method for reducing postoperative pain and time to first rescue analgesia in patients undergoing 
laparoscopic cholecystectomy. These results are consistent with our study.

In addition, El Rahmawy et al. ${ }^{(7)}$ found that prophylactic pregabalin $(150 \mathrm{mg})$ prolonged time to first rescue analgesia after spinal anesthesia.

Moreover, Rajappa et al. (16) conducted a study on 135 patients undergoing vaginal hysterectomy under spinal anesthesia. The patients were divided into three groups of 45 patients each: group 0: placebo; group 1: 75 mg pregabalin; and group 2: $150 \mathrm{mg}$ pregabalin; each treatment of which was administered one hour before surgery. Time to first rescue analgesia was assessed and it was longer in group 2.

Besides, Montaser et al. (17) conducted a study on sixty patients that were randomized into 4 groups: Group I: control (placebo) group, Group II: received pregabalin $300 \mathrm{mg} 2 \mathrm{~h}$ preoperatively, Group III: received pregabalin $300 \mathrm{mg} 2 \mathrm{~h}$ preoperatively and $12 \mathrm{~h}$ thereafter, Group IV: received pregabalin $600 \mathrm{mg} 2 \mathrm{~h}$ preoperatively. Times to first request of analgesia were recorded and it was longer in pregabalin groups.

As regard time of two segment regression, it was longer in pregabalin treated patients and this is consistent with Sebastian et al. ${ }^{(18)}$ study, which was conducted on ninety patients with ASA physical status I, II, aged between 18-50 years old. One hour prior to spinal anaesthesia group $\mathrm{C}$ received colour matched empty capsules and group $\mathrm{P}$ received $150 \mathrm{mg}$ of oral pregabalin. Time of two segment regression and time for rescue analgesia were significantly increased in group $\mathrm{P}$ than in group $\mathrm{C}$.

Also our study results are in accordance with Park $\boldsymbol{e t}$ al. ${ }^{(\mathbf{1 9 )}}$ as they noticed that preoperative administration of $150 \mathrm{mg}$ pregabalin 2 hours before spinal anesthesia prolonged the duration of both time of two segment regression and time to the first postoperative analgesic request.

At variance to our study, El Rahmawy et $\boldsymbol{a l}{ }^{(7)}$ who observed that that preemptive use of pregabalin had no effect on time of two segment regression.

As regard motor block, we observed that preoperative medication with oral pregabalin was associated with earlier onset of motor block and this is consistent with Park et al. (19) study as they have concluded that preemptive oral pregabalin before spinal anesthesia enhanced motor block

At variance to our study, Bafna et al. (20) who observed that that preemptive use of gabapentin $600 \mathrm{mg}$ and pregabalin $150 \mathrm{mg}$ orally significantly reduced time to the first postoperative analgesic request in patients undergoing elective gynecological surgeries under spinal anesthesia but had no effect on the onset of motor block.

As regard postoperative nausea and vomiting, there was lower incidence of postoperative nausea and vomiting at pregabalin-treated patients, which is consistent with many studies.

Mishriky et al. ${ }^{(21)}$ concluded that patients receiving preoperative pregabalin had less postoperative nausea and vomiting and pruritus compared to placebo group, which is in accordance with our study.

Wang et al. ${ }^{(22)}$ compared the effect of preoperative pregabalin and placebo in reducing postoperative nausea and vomiting at patients undergoing hysterectomy. They observed that postoperative nausea and vomiting were reduced in pregabalin group.

In addition, Kumar et al. ${ }^{(23)}$ study ,which was conducted on 75 patients of either sex and age group between 20-60 years old belonging to American Society of Anesthesiology-1 (ASA) and ASA-2. Patients underwent elective decompressive lumbar laminectomy under general anesthesia. The groups of this study was: group 1 (placebo) that received a placebo capsule orally 1 hour before anesthetic induction, group 2 (tramadol) which received a $100 \mathrm{mg}$ capsule orally 1 hour before the anesthetic induction and group 3 (pregabalin) that received a $150 \mathrm{mg}$ capsule orally 1 hour before the anesthetic induction. They concluded that pregabalin has a lower number of postoperative complications of nausea, vomiting, and drowsiness when compared to tramadol and placebo.

Nofal et al. ${ }^{(11)}$ study concluded that Pre-operative administration of gabapentin (structurally related compound to pregabalin) had no significant adverse effects on the mother or the baby.

Regarding shivering, it was lower in pregabalin-treated patients and this is 
consistent with Gupta $\boldsymbol{e t}$ al. ${ }^{(24)}$ study, which was conducted on patients undergoing laparoscopic cholecystectomy and they have concluded that preemptive oral pregabalin reduced the incidence of post operative shivering.

\section{CONCLUSION}

In conclusion, in our study the preoperative administration of oral pregabalin $150 \mathrm{mg}$ reduced the the incidence of postdural puncture headache, shivering, post- operative nausea and vomiting with earlier onset of motor block and increased duration of analgesia and time of two segment regression with no effect on baby (Apgar score).

\section{REFERENCES}

1. Turnbull DK, Shepherd DB (2003): Post-dural puncture headache: pathogenesis, prevention and treatment. $\mathrm{Br}$ J Anaesth., 91: 718-29.

2. Scavone BM, Wong CA, Sullivan JT, Yaghmour E, Sherwani SS, McCarthy RJ (2004): The Efficacy of a prophylactic epidural blood patch in preventing post dural puncture headache in parturients after inadvertent dural puncture. Anesthesiology, 101:1422-7.

3. Sweetman SC (2013): Martindale: The complete drug reference. London: Pharmaceutical Press. Available from: http://www. medicinescomplete.com/.

4. Alama C, Raheenb A, Iqbalc KM (2011): Headache following spinal anaesthesia: a review on recent update. J Bangladesh Coll Phys Surg., 29:32-40.

5. Faramarz M, Karimi K, Madadi F, Khoshnevis SH, Besheli L (2001): needle size, height and body mass index in postlumbar punctureheadache. Cephalalgia, 21(7):738-43.

6. Zencirci B (2010): Postdural puncture headache and pregabalin. J Pain Res., 3:11-4.

7. El Rahmawy G, Rashwan D, Mohamed NN (2013): The efficacy of preoperative pregabalin on reduction of the incidence and severity of postdural puncture headache after spinal anesthesia. Egyptian Journal of Anaesthesia, 29(4):357-61.

8. Huseyinoglu $\mathbf{U}$, Huseyinoglu $\mathbf{N}$, Hamurtekin E, Aygun H, Sulu B (2011):
Effect of pregabalin on post-duralpuncture headache following spinal anesthesia and lumbar puncture. Journal of Clinical Neuroscience, 18(10):1365-8.

9. Mahoori A, Noroozinia H, Hasani E, Saghaleini H (2014): Comparing the effect of pregabalin, gabapentin, and acetaminophen on post-dural puncture headache. Saudi J Anaesth., 8: 374-7.

10. Moghaddam M, Mirkheshti A, Yahyavi $P$ (2011): Comparison between analgesic effect of gabapentin and pregabalin in controlling delayed onset Post Dural Puncture Headache in non-pregnant patients: 14AP6-1. European Journal of Anaesthesiology (EJA), 28:203-4.

11. Nofal WH, Mahmoud MS, Al Alim AA (2014): Does preoperative gabapentin affects the characteristics of post-dural puncture headache in parturients undergoing cesarean section with spinal anesthesia? Saudi Journal of Anaesthesia, 8(3):359.

12. Induja R, Asha B, Bikash RM, Srikanth S (2014): Prospective, randomised, double blinded controlled trial of gabapentin and pregabalin as pre emptive analgesia in patients undergoing lower abdominal and limb surgery under spinal anaesthesia, Indian Journal of Pain, 28 (3): 15-25.

13. Ghai A, Gupta $M$, Rana $N$, Wadhera $R$ (2012) : The effect of pregabalin and gabapentin on preoperative anxiety and sedation: a double blind study. Anaesth Pain \& Intensive Care, 16(3):257-261.

14. Jokela R, Ahonen J, Tallgren M, Haanpää M, Korttila K (2008): A randomized controlled trial of perioperative administration of pregabalin for pain after laparoscopic hysterectomy. Pain, 134:106-12.

15. Agarwal A, Gautam S, Gupta D, Agarwal S, Singh PK, Singh U (2008): Evaluation of a single preoperative dose of pregabalin for attenuation of postoperative pain after laparoscopic cholecystectomy. Br J Anaesth., 101:700-4.

16. Rajappa GC, Vig S, Bevanaguddaiah $Y$, Anadaswamy TC (2016): Efficacy of pregabalin as premedication for postoperative analgesia in vaginal hysterectomy. Anesthesiology and Pain Medicine, 6(3): 13-63. 
17. Montaser AM, Ahmed HO, Ahmad MA (2016): Analgesic efficacy and safety of peri-operative pregabalin following radical cystectomy: A dose grading study. Egyptian Journal of Anaesthesia, 32(4):513-7.

18. Sebastian B, Talikoti AT, Nelamangala K, Krishnamurthy D (2016): Effect of oral pregabalin as preemptive analgesic in patients undergoing lower limb orthopedic surgeries under spinal anaesthesia. Journal of clinical and diagnostic research, 10(7):UC01.

19. Park M, Jeon Y (2016): Preoperative pregabalin prolongs duration of spinal anesthesia and reduces early postoperative pain: A double-blind, randomized clinical CONSORT study. Medicine, 95(36): 1826.

20. Bafna U, Rajarajeshwaran $K$, Khandelwal M, Verma AP (2014): A comparison of effect of preemptive use of oral gabapentin and pregabalin for acute post-operative pain after surgery under spinal anesthesia. Journal of anaesthesiology, Clinical Pharmacology, 30(3):373.

21. Mishriky B, Waldron $\mathbf{N}$, Habib A (2014): Impact of pregabalin on acute and persistent postoperative pain: a systematic review and meta-analysis. British Journal of Anaesthesia, 114(1):10-31.

22. Wang Y, Xia M, Shan N, Yuan P, Wang $\mathrm{D}$, Shao J, et al. (2017): Pregabalin can decrease acute pain and postoperative nausea and vomiting in hysterectomy: A meta-analysis. Medicine, 96(31): 24-32.

23. Kumar KP, Kulkarni DK, Gurajala I, Gopinath R (2013): Pregabalin versus tramadol for postoperative pain management in patients undergoing lumbar laminectomy: a randomized, double-blinded, placebo-controlled study. Journal of Pain Research, 6:471.

24. Gupta K, Sharma D, Gupta PK (2011): Oral premedication with pregabalin or clonidine for hemodynamic stability during laryngoscopy and laparoscopic cholecystectomy: A comparative evaluation. Saudi Journal of Anaesthesia, 5(2):179. 